\title{
The role of whole brain radiation therapy in the management of newly diagnosed brain metastases: a systematic review and evidence-based clinical practice guideline
}

\author{
Laurie E. Gaspar · Minesh P. Mehta • Roy A. Patchell $\cdot$ Stuart H. Burri • \\ Paula D. Robinson - Rachel E. Morris - Mario Ammirati - David W. Andrews • \\ Anthony L. Asher $\cdot$ Charles S. Cobbs $\cdot$ Douglas Kondziolka $\cdot$ Mark E. Linskey \\ Jay S. Loeffler • Michael McDermott · Tom Mikkelsen · Jeffrey J. Olson • \\ Nina A. Paleologos • Timothy C. Ryken $\cdot$ Steven N. Kalkanis
}

Received: 7 September 2009/Accepted: 8 November 2009/Published online: 4 December 2009

(C) The Author(s) 2009. This article is published with open access at Springerlink.com

\begin{abstract}
Should whole brain radiation therapy (WBRT) be used as the sole therapy in patients with newly-diagnosed, surgically accessible, single brain metastases, compared with WBRT plus surgical resection, and in what clinical settings?

Target population

This recommendation applies to adults with newly diagnosed single brain metastases amenable to surgical resection; however, the recommendation does not apply to relatively radiosensitive tumors histologies (i.e., small cell lung cancer, leukemia, lymphoma, germ cell tumors and multiple myeloma).

\section{Recommendation}

\section{Surgical resection plus WBRT versus WBRT alone}

Level 1 Class I evidence supports the use of surgical resection plus post-operative WBRT, as compared to WBRT alone, in patients with good performance status (functionally independent and spending less than $50 \%$ of time in bed) and limited extra-cranial disease. There is insufficient evidence to make a recommendation for patients with poor performance scores, advanced systemic disease, or multiple brain metastases.

If WBRT is used, is there an optimal dosing/fractionation schedule?
\end{abstract}

Target population

This recommendation applies to adults with newly diagnosed brain metastases.

\section{Recommendation}

Level 1 Class I evidence suggests that altered dose/fractionation schedules of WBRT do not result in significant differences in median survival, local control or

L. E. Gaspar

Department of Radiation Oncology, University of Colorado-

Denver, Denver, CO, USA neurocognitive outcomes when compared with "standard" WBRT dose/fractionation. (i.e., 30 Gy in 10 fractions or a biologically effective dose (BED) of 39 Gy10).

If WBRT is used, what impact does tumor histopathology have on treatment outcomes?

Target population

This recommendation applies to adults with newly diagnosed brain metastases.

\section{Recommendation}

Given the extremely limited data available, there is insufficient evidence to support the choice of any particular dose/fractionation regimen based on histopathology.

The following question is fully addressed in the surgery guideline paper within this series by Kalkanis et al. Given that the recommendation resulting from the systematic review of the literature on this topic is also highly relevant to the discussion of the role of WBRT in the management of brain metastases, this recommendation has been included below.

Does the addition of WBRT after surgical resection improve outcomes when compared with surgical resection alone?

Target population

This recommendation applies to adults with newly diagnosed single brain metastases amenable to surgical resection.

Recommendation

Surgical resection plus WBRT versus surgical resection alone

Level 1 Surgical resection followed by WBRT represents a superior treatment modality, in terms of improving tumor control at the original site of the metastasis and in the brain overall, when compared to surgical resection alone.

M. P. Mehta

Department of Human Oncology, Universtity of Wisconsin School of Public Health and Medicine, Madison, WI, USA 
Keywords Brain metastases .

Whole brain radiation therapy - Radiotherapy .

Surgical resection - Fractionation · Histopathology ·

Systematic review · Practice guideline

\section{Rationale}

Whole-brain radiation therapy (WBRT) has long been a standard treatment for patients with brain metastases. Based on preclinical and observational data, some physicians alter dose fractionation or withhold WBRT based upon tumor histology.

This paper will systematically review the evidence available for altered WBRT dose fractionation and the impact of tumor histopathology on treatment outcomes when WBRT is used. In addition, this paper will also systematically review the evidence for the use of surgical resection plus WBRT compared with WBRT alone in patients with newly diagnosed, surgically accessible, single brain metastases. The studies identified through this process will be used to make evidence-based recommendations for

R. A. Patchell

Department of Neurology, Barrow Neurological Institute, Phoenix, AZ, USA

\section{S. H. Burri}

Department of Radiation Oncology, Carolinas Medical Center, Charlotte, NC, USA

P. D. Robinson · R. E. Morris

McMaster University Evidence-Based Practice Center,

Hamilton, ON, Canada

M. Ammirati

Department of Neurosurgery, Ohio State University Medical

Center, Columbus, OH, USA

D. W. Andrews

Department of Neurosurgery, Thomas Jefferson University, Philadelphia, PA, USA

\section{A. L. Asher}

Department of Neurosurgery, Carolina Neurosurgery and Spine Associates, Charlotte, NC, USA

\section{S. Cobbs}

Department of Neurosciences, California Pacific Medical Center, San Francisco, CA, USA

D. Kondziolka

Department of Neurological Surgery, University of Pittsburgh Medical Center, Pittsburgh, PA, USA the role of WBRT in the management of patients with newly diagnosed brain metastases.

As WBRT has been a mainstay of the treatment approach for patients with brain metastases, several other papers in this guideline series also include comparisons and recommendations regarding the use of WBRT for this patient population. Of particular note are the papers by Kalkanis et al. [1], (surgical resection) and Linskey et al. [2], (stereotactic radiosurgery) for patients with newly diagnosed brain metastases.

\section{Methods}

\section{Search strategy}

The following electronic databases were searched from 1990 to September 2008: MEDLINE $^{\circledR}$, Embase $^{\circledR}$, Cochrane Database of Systematic Reviews, Cochrane Controlled Trials Registry, and Cochrane Database of Abstracts of Reviews of Effects. A broad search strategy using a combination of subheadings and text words was employed. The search strategy is documented in the methodology

M. E. Linskey

Department of Neurosurgery, University of California-Irvine Medical Center, Orange, CA, USA

J. S. Loeffler

Department of Radiation Oncology, Massachusetts General

Hospital, Boston, MA, USA

M. McDermott

Department of Neurosurgery, University of California San

Francisco, San Francisco, CA, USA

T. Mikkelsen

Department of Neurology, Henry Ford Health System, Detroit, MI, USA

J. J. Olson

Department of Neurosurgery, Emory University School of Medicine, Atlanta, GA, USA

N. A. Paleologos

Department of Neurology, Northshore University Health

System, Evanston, IL, USA

T. C. Ryken

Department of Neurosurgery, Iowa Spine and Brain Institute, Iowa City, IA, USA

S. N. Kalkanis $(\bowtie)$

Department of Neurosurgery, Henry Ford Health System, Hermelin Brain Tumor Center, 2799 West Grand Blvd, K-11, Detroit, MI 48202, USA

e-mail: kalkanis@neuro.hfh.edu; skalkan1@hfhs.org 
paper for this guideline series by Robinson et al. [3] Reference lists of included studies were also reviewed.

Eligibility criteria

(a) For WBRT versus surgical resection plus WBRT question:

- Published in English with a publication date of 1990 forward.

- Patients with newly diagnosed single brain metastases.

- Fully published peer-reviewed primary comparative studies (all comparative study designs for primary data collection included; e.g., randomized controlled trials (RCTs), non-randomized trials, cohort studies or case-control studies)

- Study comparisons include: WBRT versus surgery + WBRT

- Number of participants with newly diagnosed brain metastases $>5$ per study arm

- Baseline information on study participants is provided by treatment group in studies evaluating interventions exclusively in patients with newly diagnosed brain metastases. For studies with mixed populations (i.e., includes participants with conditions other than newly diagnosed brain metastases), baseline information is provided for the intervention sub-groups of participants with newly diagnosed brain metastases.

(b) For optimal dosing/fractionation schedule for WBRT question:

- Published in English.

- Patients with newly diagnosed brain metastases.

- Fully published peer-reviewed primary comparative studies (all comparative study designs for primary data collection included; e.g., RCT, nonrandomized trials, cohort studies or case-control studies) for studies published 1990 forward; RCTs published 1970 forward.

- Study comparisons include: WBRT dose/fractionation schedule 1 versus WBRT dose/fractionation schedule 2

- Number of participants with newly diagnosed brain metastases $>5$ per study arm.

- Baseline information on study participants is provided by treatment group in studies evaluating interventions exclusively in patients with newly diagnosed brain metastases. For studies with mixed populations (i.e., includes participants with conditions other than newly diagnosed brain metastases), baseline information is provided for the intervention sub-groups of participants with newly diagnosed brain metastases.

(c) For whether tumor histopathology has an impact on WBRT treatment outcomes?

- Published in English with a publication date of 1990 forward.

- Patients with newly diagnosed brain metastases.

- Fully published peer-reviewed primary studies (all study designs for primary data collection included; e.g., RCT, non-randomized trials, cohort studies, case-control studies or case series).

- Any study evaluating the outcome(s) of WBRT by tumor histopathology (or primary tumor type).

- Number of participants with newly diagnosed brain metastases $>5$ per study arm for comparative studies and $>5$ overall for non-comparative studies.

- For studies evaluating the outcome(s) of WBRT by histopathology (or primary tumor type) exclusively in patients with newly diagnosed brain metastases, baseline characteristics are presented and stratified by histologic/primary tumor group. For studies with mixed populations (i.e., includes participants with conditions other than newly diagnosed brain metastases), baseline characteristics are presented and stratified by histologic/ primary tumor group for the sub-group of participants with newly diagnosed brain metastases.

Study selection and quality assessment

Two independent reviewers evaluated citations using a priori criteria for relevance and documented decisions in standardized forms. Cases of disagreement were resolved by a third reviewer. The same methodology was used for full text screening of potentially relevant papers. Studies which met the eligibility criteria were data extracted by one reviewer and the extracted information was checked by a second reviewer. The PEDro scale $[4,5]$ was used to rate the quality of randomized trials. The quality of comparative studies using non-randomized designs was evaluated using eight items selected and modified from existing scales.

Meta-analyses

Meta-analyses of RCTs were undertaken when sufficient data for pooling was available for the outcomes of interest. For the following outcomes, 6 month mortality, overall survival and neurologic function, the altered WBRT dose/ fractionation schedules were compared to conventional scheduling. The pooled relative risk (RR) was estimated using a random-effects model and each RCT was weighted 
by the inverse of its variance. Chi-square heterogeneity tests were used to test for statistical heterogeneity amongst the RCTs. $I^{2}$ was calculated in order to quantify inconsistency across trials and assess the impact of heterogeneity on the meta-analysis. Publication bias was evaluated graphically with funnel plots. All statistical analyses were carried out using Revman 5.

Evidence classification and recommendation levels

Both the quality of the evidence and the strength of the recommendations were graded according to the American Association of Neurological Surgeons (AANS)/Congress of Neurological Surgeons (CNS) criteria. These criteria are provided in the methodology paper for this guideline series.
Guideline development process

The AANS/CNS convened a multi-disciplinary panel of clinical experts to develop a series of practice guidelines on the management of brain metastases based on a systematic review of the literature conducted in collaboration with methodologists at the McMaster University Evidencebased Practice Center.

\section{Scientific foundation}

Overall, 24 primary studies [6-29] and seven companion papers [30-36] met the eligibility criteria for this systematic review (Fig. 1).
Fig. 1 Flowchart of studies to final number of eligible studies

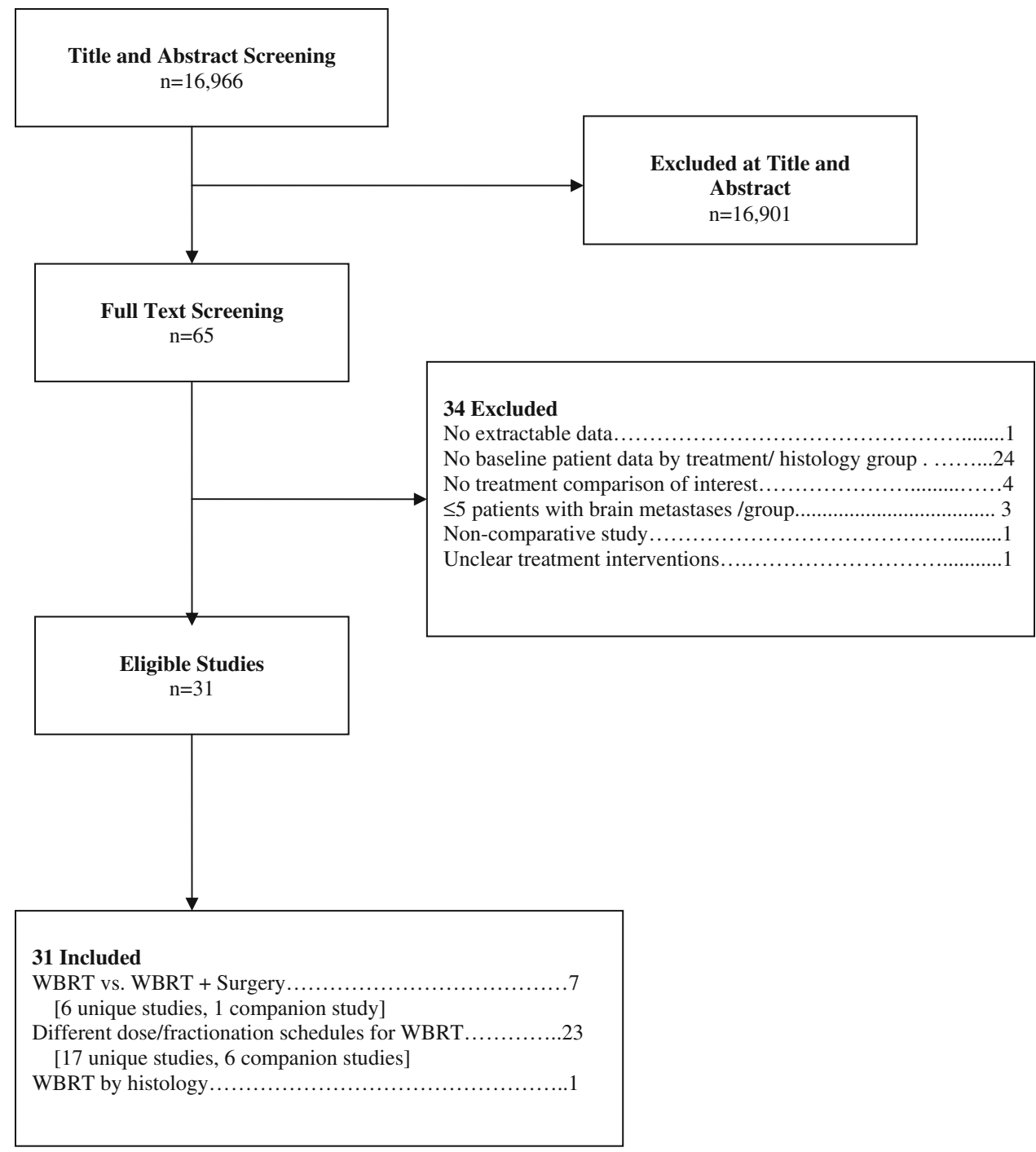


Surgical Resection plus WBRT versus WBRT alone

Seven studies met the eligibility criteria for this treatment comparison, and of these six were unique and one was a companion study $[6-11,30]$. Three of these studies were prospective randomized trials [6-8] (Table 1). Given that the treatment modalities being compared included surgical resection in only one arm of each trial, all of the RCTs were non-blinded. In a randomized trial performed at the University of Kentucky [6], 48 patients with known systemic cancer were treated with either biopsy of the suspected brain metastasis plus WBRT or complete surgical resection of the metastasis plus WBRT. The radiation doses were the same in both groups and consisted of a total dose of 36 Gy given in 12 daily fractions of 3 Gy each. Patients had to be capable of caring for themselves independently, with a Karnofsky performance score (KPS) of at least 70. Patients were ineligible if they had a need for immediate treatment to prevent acute neurologic deterioration, or if they had tumors considered to be relatively radiosensitive [small cell lung cancer (SCLC), germ-cell tumors, lymphoma, leukemia, and multiple myeloma]. Patients were not excluded based on the extent of systemic disease. Randomization was performed by computer-generated random numbers. Information on allocation concealment was not reported. All the patients in the surgical group were considered to have had complete resection as assessed by postoperative computerized tomography (CT) scanning. Follow up brain CT or magnetic resonance imaging (MRI) scans were required every 3 months. There was a statistically significant increase in survival in the surgical group (40 vs. 15 weeks). In addition, the time to recurrence of brain metastases, freedom from death due to neurologic causes, and duration of functional independence were significantly longer in the surgical resection group. The 1 month mortality was $4 \%$ in each group, indicating that there was no extra mortality from surgery. Although surgical resection was the only variable positively associated with maintaining performance status, the extent of systemic disease and increased age were associated with poor performance status post-treatment.

A second randomized study [8], conducted as a multiinstitutional trial in the Netherlands, contained 63 evaluable patients. Patients with single brain metastases were randomized to complete surgical resection plus WBRT or WBRT alone. Randomization was performed centrally by telephone. The WBRT schedules were the same for both treatment arms and consisted of $40 \mathrm{~Gy}$ given in a nonstandard fractionation scheme of 2 Gy twice per day for 2 weeks (10 treatment days). Patients had to have a reasonable quality of life and neurological status, defined as spending no more than $50 \%$ of their time in bed and not requiring continuous nursing care or hospitalization.
Excluded histologies were SCLC and lymphoma. Information is not given regarding the extent of resection in the surgical group or the use and frequency of imaging in follow up. Survival was significantly longer in the surgical group (10 vs. 6 months). There was also a non-significant trend toward longer duration of functional independence in the surgically treated patients. No data concerning recurrence of brain metastases were provided. The 1 month mortality rates were $9 \%$ in the surgery group and $0 \%$ in the WBRT alone group, a statistically insignificant difference. The authors concluded that the addition of surgery to WBRT provided a survival benefit except to those patients who were 60 years of age or older, or those patients with progressive systemic disease in the 3 months prior to the diagnosis of the brain metastasis.

A third randomized trial, conducted as a multi-center trial in Canada by Mintz et al. [7], failed to find a benefit from surgical treatment. In that study, 84 patients with a single brain metastasis were randomized to receive radiotherapy alone ( 30 Gy given in 10 daily fractions of $3 \mathrm{~Gy}$ ) or surgery plus radiotherapy. Randomization was performed centrally by telephone. Eligible patients had to be less than 80 years of age, and they had to have a KPS of at least 50, i.e., they could be spending more than $50 \%$ of their time in bed but had to be able to care for some personal needs. Patients were not eligible if they had leukemia, lymphoma, or SCLC. A CT scan was done in the first postoperative week to assess the extent of tumor removed. Follow up CT scans were performed monthly for 6 months and every 3 months after that. A gross total resection was achieved in 38 of the 40 patients in the surgical group. No difference was found in overall survival; the median survival time was 6.3 months in the radiotherapy alone group and 5.6 months for the surgical group. There was also no difference in causes of death or quality of life.

It is unclear why the Canadian study was not in agreement with the other two trials. In all three studies, the control arms (the radiation alone arms) had median lengths of survival in the 3-6 months range-within the expected range for patients treated with radiotherapy alone. The major difference in the studies was the poor results obtained in the surgical arm of the Canadian trial. That study contained a higher proportion of patients with extensive systemic disease and lower performance scores. It is possible that these factors resulted in more patients dying of their systemic cancer before a long term benefit of surgery was seen. Additionally, MRI was not mandatory in the Canadian study, and it is theoretically possible that patients with additional lesions not detected by CT may have been included in the study.

All three of the evidence class II studies [9-11] demonstrated a survival benefit for patients who underwent surgical resection followed by WBRT as compared to 


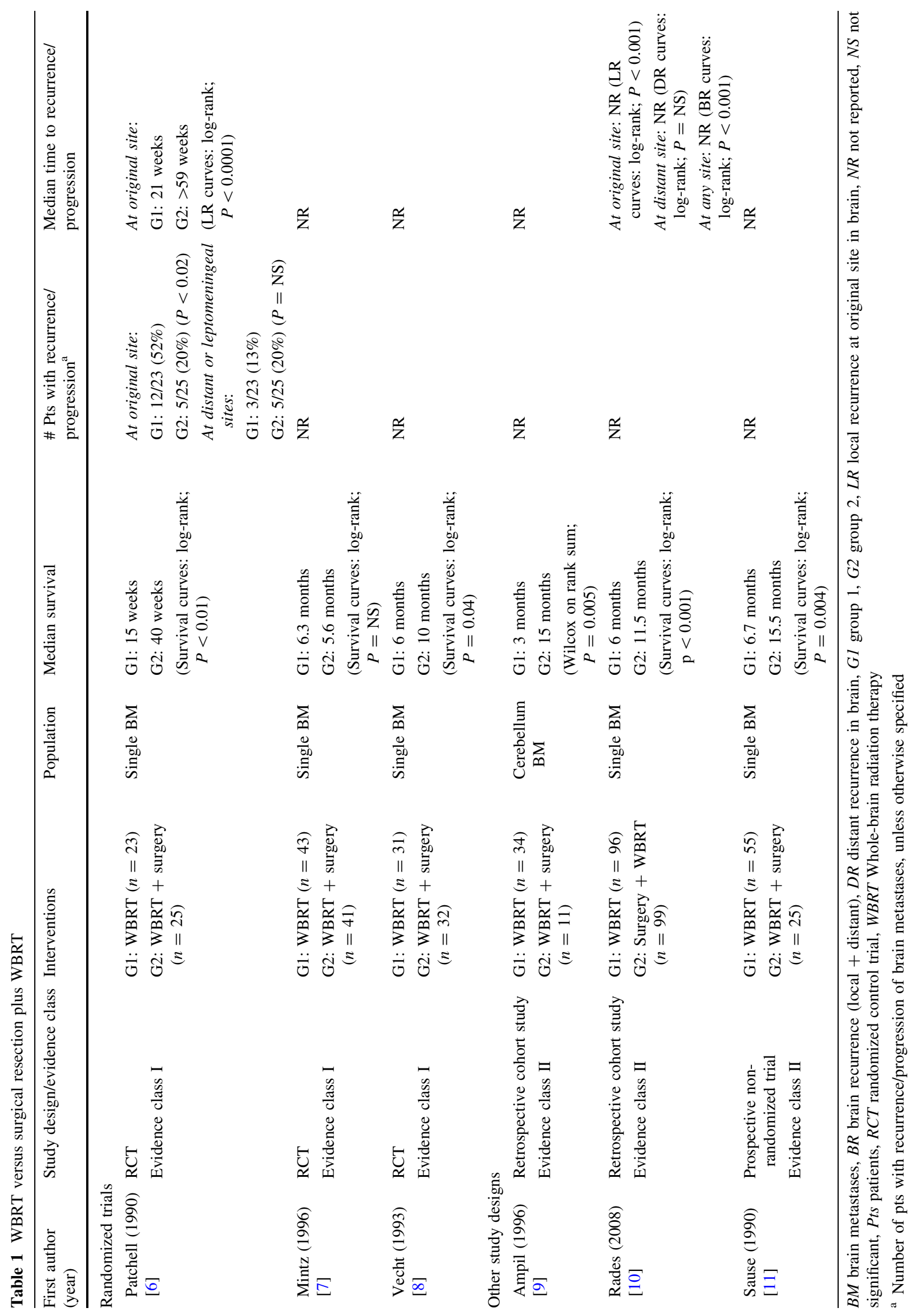


WBRT alone. Ampil et al., published a single institution experience with either surgery plus WBRT (11 patients) versus WBRT alone (34 patients) in 45 patients who had a cerebellar metastasis. The majority of the patients in the WBRT alone arm had additional supratentorial brain metastases. Although there was a significant difference in survival noted between the two groups, the authors concluded that the outcome of patients with a brain metastasis within the cerebellum was improved with surgical resection if the primary was not from the lung.

\section{WBRT dosing/fractionation schedule}

Twenty-three studies met the eligibility criteria for this question, and of these, 17 were unique [12-28] and six [31$36]$ were companion publications (Table 2). The 17 unique studies fell into three AANS/CNS evidence class categories as follows: ten class I studies (nine RCTs [12-20] and one randomized phase I/II trial [21]), six class II studies [22-24, 26-28] (retrospective cohort studies) and one class III study [25] (prospective cohort study with historical controls).

The radiation dosages have been expressed in terms of the tumor response biologically effective dose (BED) in order to quantitatively capture the observed biological effect between treatment arms. This was calculated from the linear quadratic equation:BED $=n d[1+d /(\alpha / \beta)]$ where $n=$ number of treatments, $d=$ dose per fraction; the calculation assumes $\alpha / \beta=10$ Gy for tumor effects of each schedule, however it is uncorrected for treatment regimes of two fractions/day. The BED units are referred to in terms of $\mathrm{Gy}_{10}$ to indicate that the BED values are singlepoint calculations for tumor response [37, 38] and no correction for accelerated repopulation was made.

Expressing radiation dosages in terms of the BED takes into account the total dose of radiation, fraction size, and overall time to deliver the radiation, and presumed repair of irradiated tissue. The analyses are stratified by low or high dose versus control dose. The control group consists of patients treated with $30 \mathrm{~Gy}$ in 10 fractions for a BED $=39$ $\mathrm{Gy}_{10}$ (therefore assigning the low dose regimens as a BED $<39 \mathrm{~Gy}_{10}$, and high dose regimens as a $\left.\mathrm{BED}>39 \mathrm{~Gy}_{10}\right)$.

None of the trials demonstrated a meaningful improvement in any endpoint relative to dose; specifically, survival was not improved. There was considerable overlap in terms of survival even at the same dose level in different trials, underscoring the significance of host-specific variables in determining survival.

The data from the randomized trials, stratified by the BED are shown in Table 3.

The meta-analyses were stratified by low or high dose versus control dose. Studies lacking a comparable control were excluded from meta-analyses, due to the inherent dosing variability amongst the study's control group.
Figure 2 indicates the RR of mortality at 6 months in the low dose (BED $<39 \mathrm{~Gy}_{10}$ ) group compared to that in the WBRT control group $\left(\mathrm{BED}=39 \mathrm{~Gy}_{10}\right)$. Only data from two trials (Chantani et al. [13] and Priestman et al. [20]) were robust enough to be considered for this end-point. When combined, no difference $(P=0.52)$ was found for 6 month mortality (RR $1.05 ; 95 \%$ CI $0.90,1.23$ ). Figure 3 presents the same analysis, but for the comparison of the high dose (BED > $39 \mathrm{~Gy}_{10}$ ) group to the WBRT control group $\left(\mathrm{BED}=39 \mathrm{~Gy}_{10}\right)$. Data from five trials were robust enough to be considered for this end-point. Combining data for Chantani et al. [13, 14], Komarnicky et al. [17], Kurtz et al. [18], and Murray et al. [19], yielded no difference $(P=0.39)$ in 6 month mortality (RR 1.05 ; 95\% CI 0.94 , 1.18). A 1981 trial by Borgelt et al. [12] was excluded from the meta-analyses for lack of a comparable control. Since the administered dosage ranged from 20 to 40 Gy over 14 weeks, the resulting permutations and combinations of plausible radiation schedules in this group varied too substantially (22-72 $\mathrm{Gy}_{10}$ ) to function as a true control. The inherent dosing variability disqualified this control group thereby making the trial ineligible for comparison.

Similar comparisons were made for overall survival and neurologic function, and no dose-effect was identified for either end-point. Figures 4 and 5 depict the overall survival for the respective comparisons of low and high BED values versus the control BED. In Fig. 4, the pooling of two studies, Chantani et al. [13] and Priestman et al. [20], for the comparison of low dose WBRT (BED $<39 \mathrm{~Gy}_{10}$ ) to a control dose $\left(\mathrm{BED}=39 \mathrm{~Gy}_{10}\right)$ yielded no difference $(P=0.07)$ in overall survival (RR $0.86 ; 95 \%$ CI 0.73 , 1.01). In Fig. 5, overall survival data from Chantani et al. [13, 14], Komarnicky et al. [17], Kurtz et al. [18], and Murray et al. [19], were pooled for the comparison of high dose WBRT $\left(\mathrm{BED}>39 \mathrm{~Gy}_{10}\right)$ versus WBRT control dose $\left(\mathrm{BED}=39 \mathrm{~Gy}_{10}\right)$. No difference $(P=0.26)$ in overall survival was found (RR 1.06; 95\% CI 0.96, 1.18). The hazard plots for neurologic function are not presented.

Impact of tumor histopathology on WBRT treatment outcomes

Using the AANS/CNS evidence classification, no papers with class I or II evidence were identified by the systematic literature review that met the eligibility criteria for this question. In fact, only one paper, providing class III evidence, met the inclusion criteria (Table 4). The only data is provided by a single institution retrospective analysis with 75 cases (Sundstrom et al. [29]). In that study, there were 15 cases that were of classic "radio-resistant" histology. There were no statistically significant differences in overall survival by tumor histology. Local control by tumor type was not reported. 


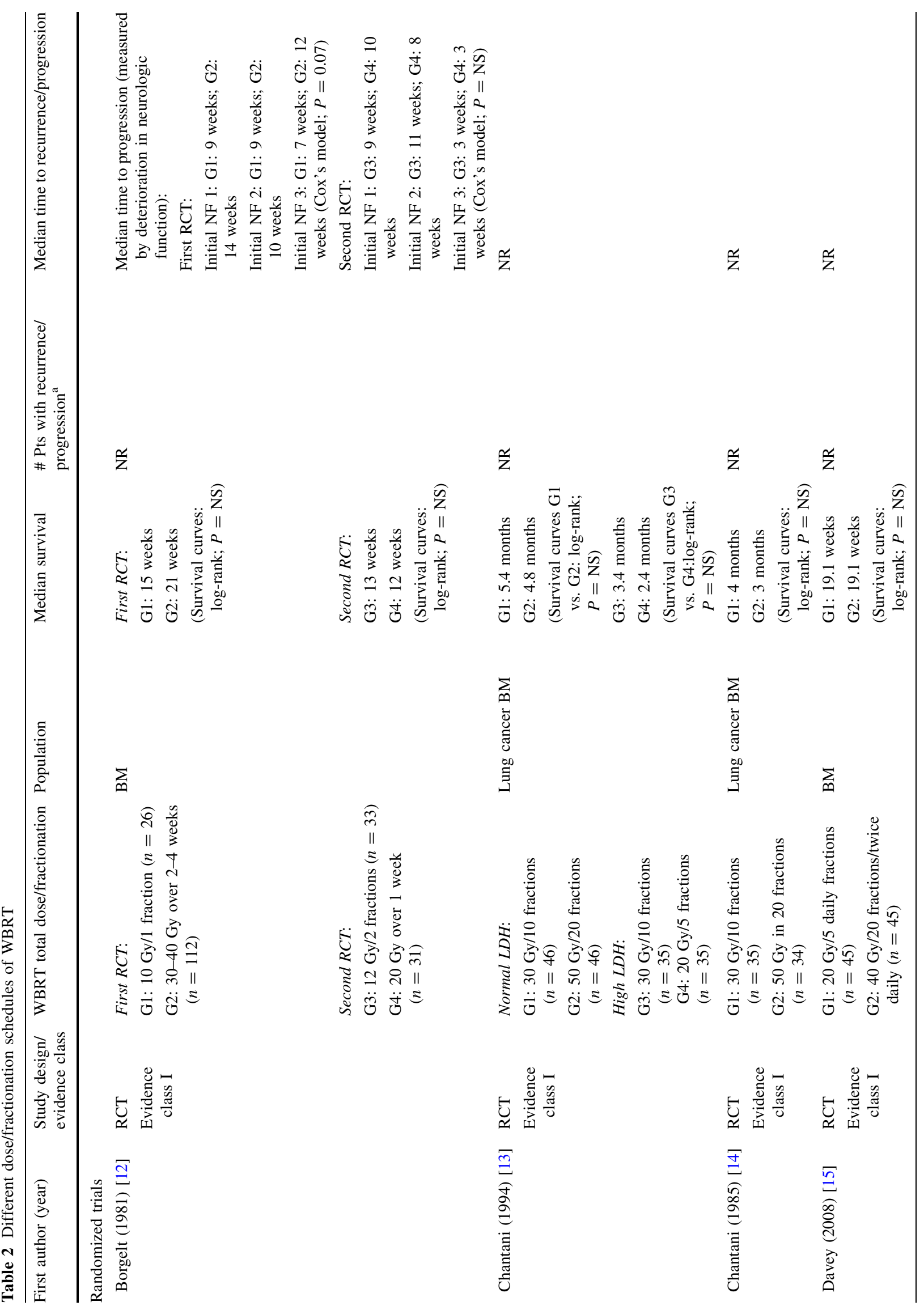




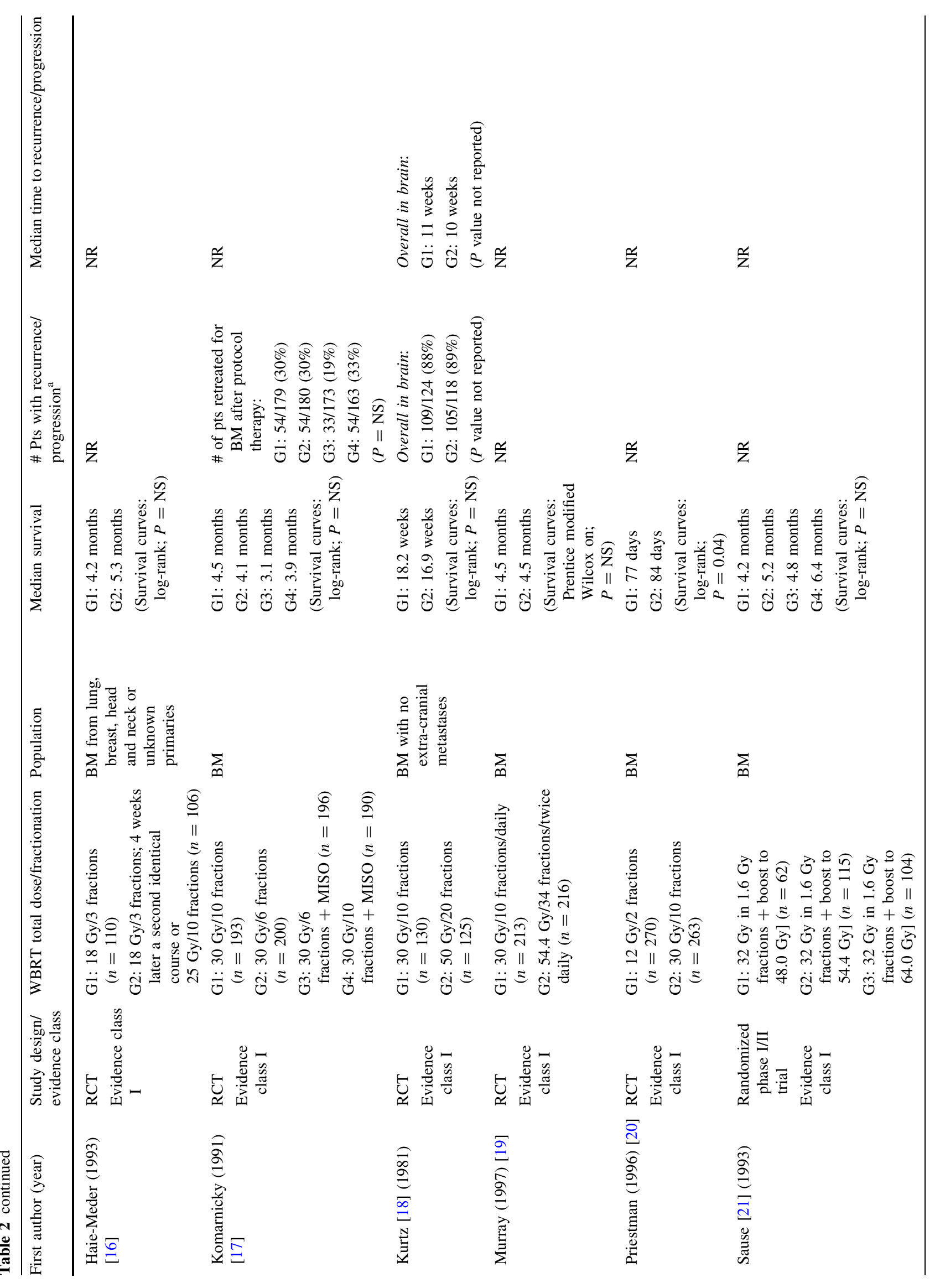




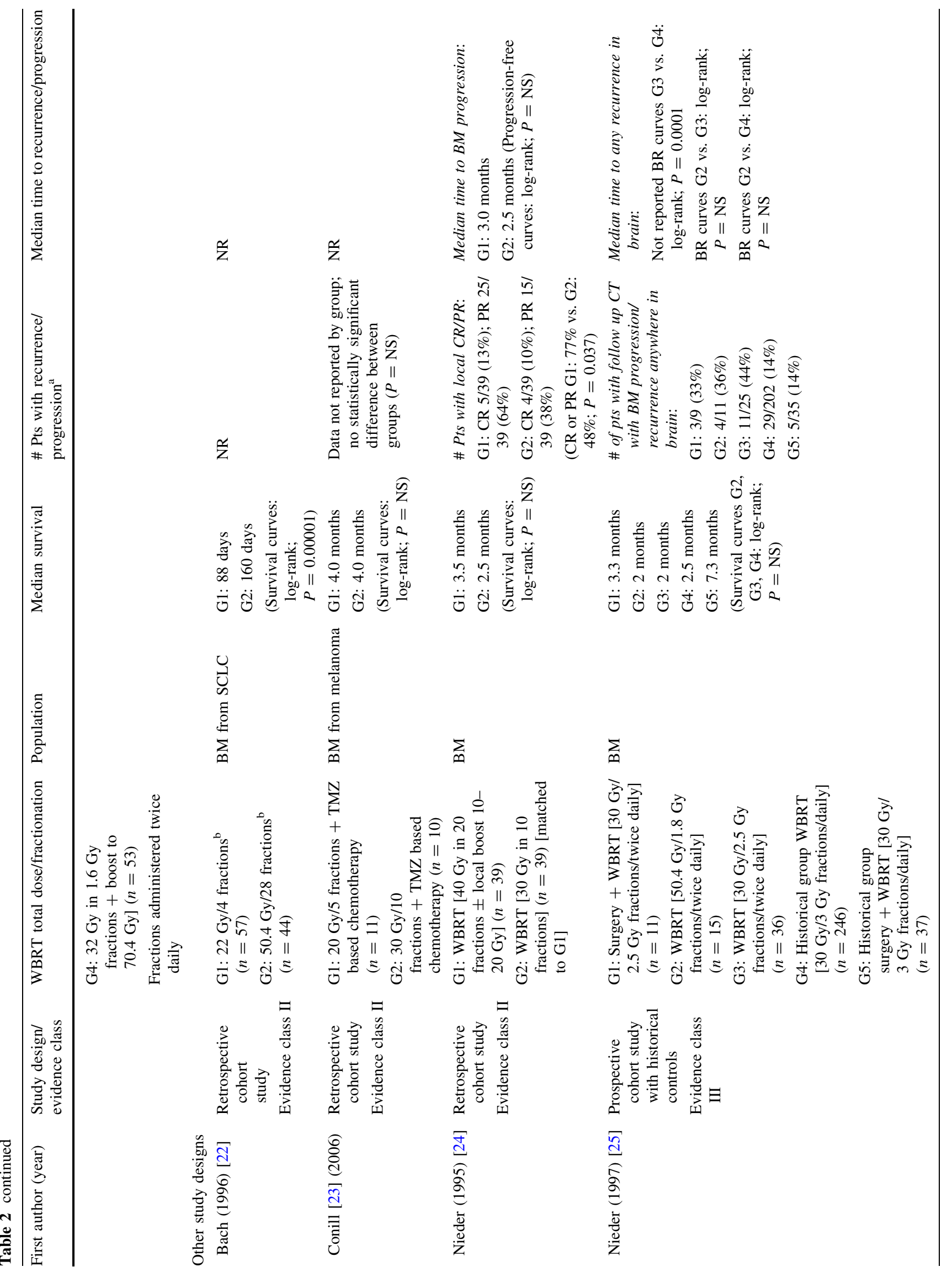




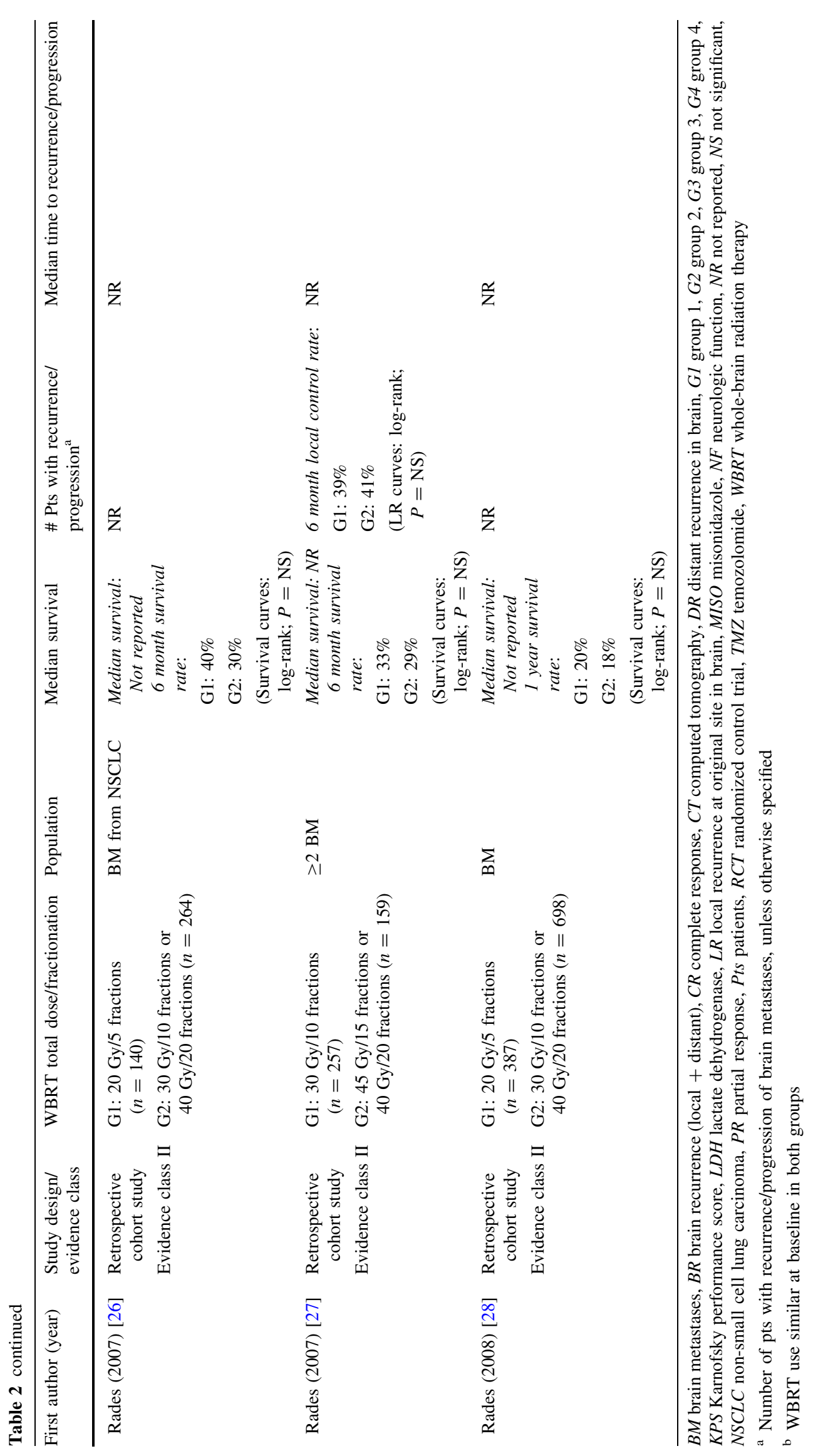


Table 3 Randomized trials stratified by the BED for different treatment schedules

\begin{tabular}{|c|c|c|c|c|c|c|c|}
\hline \multirow{2}{*}{$\begin{array}{l}\text { Table } 3 \text { Randomized trials } \\
\text { stratified by the BED for } \\
\text { different treatment schedules }\end{array}$} & Author & Year & $\begin{array}{l}\text { Total } \\
\text { dose (Gy) }\end{array}$ & Fractions & $\begin{array}{l}\mathrm{BED}(\mathrm{Gy} ; \\
\alpha / \beta=10)\end{array}$ & $n$ & $\begin{array}{l}\text { Median survival } \\
\text { (weeks) }\end{array}$ \\
\hline & Borgelt & 1981 & 12 & 2 & 19.2 & 33 & 13 \\
\hline & Priestman & 1996 & 12 & 2 & 19.2 & 270 & 11 \\
\hline & Borgelt & 1981 & 10 & 1 & 20 & 26 & 15 \\
\hline & Borgelt & 1981 & 20 & 5 & 28 & 31 & 12 \\
\hline & Chatani & 1994 & 20 & 5 & 28 & 35 & 10.4 \\
\hline & Davey & 2008 & 20 & 5 & 28 & 45 & 19.1 \\
\hline & Haie-Meder & 1993 & 18 & 3 & 28.8 & 110 & 18.3 \\
\hline & Chatani & 1994 & 30 & 10 & 39 & 46 & 23.5 \\
\hline & Chatani & 1994 & 30 & 10 & 39 & 35 & 14.8 \\
\hline & Chatani & 1985 & 30 & 10 & 39 & 35 & 17.4 \\
\hline & Komarnicky & 1991 & 30 & 10 & 39 & 193 & 19.5 \\
\hline & Komarnicky & 1991 & 30 & 10 & 39 & 190 & 16.9 \\
\hline & Kurtz & 1981 & 30 & 10 & 39 & 130 & 18.2 \\
\hline & Murray & 1997 & 30 & 10 & 39 & 213 & 19.6 \\
\hline & Priestman & 1996 & 30 & 10 & 39 & 263 & 12 \\
\hline & Komarnicky & 1991 & 30 & 6 & 45 & 200 & 17.8 \\
\hline & Komarnicky & 1991 & 30 & 6 & 45 & 196 & 13.5 \\
\hline & Davey & 2008 & 40 & $20^{\mathrm{a}}$ & 48 & 45 & 19.1 \\
\hline & Sause & 1993 & 48 & $30^{\mathrm{a}}$ & 55.7 & 62 & 18.3 \\
\hline & Haie-Meder & 1993 & - & - & 50.8 & 106 & 23 \\
\hline & Chatani & 1994 & 50 & 20 & 62.5 & 46 & 20.9 \\
\hline & Chatani & 1985 & 50 & 20 & 62.5 & 34 & 13 \\
\hline & Kurtz & 1981 & 50 & 20 & 62.5 & 125 & 16.9 \\
\hline & Murray & 1997 & 54.4 & $34^{\mathrm{a}}$ & 63.1 & 216 & 19.6 \\
\hline & Sause & 1993 & 54.4 & $34^{\mathrm{a}}$ & 63.1 & 115 & 22.6 \\
\hline & Sause & 1993 & 64 & $40^{\mathrm{a}}$ & 74.2 & 104 & 20.9 \\
\hline \multirow{2}{*}{$\begin{array}{l}\text { a Treatment regimes of two } \\
\text { fractions/day (BED } \\
\text { uncorrected) }\end{array}$} & Sause & 1993 & 70.4 & $44^{\mathrm{a}}$ & 81.7 & 53 & 27.8 \\
\hline & Borgelt & 1981 & $30-40$ & $10-20$ & $34.5-56$ & 112 & 21 \\
\hline
\end{tabular}

${ }^{a}$ Treatment regimes of two fractions/day (BED uncorrected)

\begin{tabular}{|c|c|c|c|c|c|}
\hline \multirow[b]{2}{*}{ Study or Subgroup } & \multicolumn{2}{|c|}{ Low dose } & \multicolumn{2}{|c|}{ Control dose } & \multirow[b]{2}{*}{ Weight } \\
\hline & Events & Total & Events & Total & \\
\hline Chatani 1994 & 27 & 35 & 29 & 35 & $29.5 \%$ \\
\hline Priestman 1996 & 224 & 270 & 197 & 263 & $70.5 \%$ \\
\hline Total $(95 \% \mathrm{Cl})$ & & 305 & & 298 & $100.0 \%$ \\
\hline Total events & 251 & & 226 & & \\
\hline
\end{tabular}

Risk Ratio

M-H, Random, 95\% Cl

$0.93[0.74,1.18]$

$1.11[1.01,1.21]$

$1.05[0.90,1.23]$

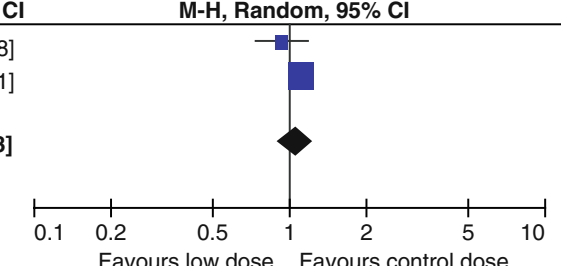

Fig. 2 Comparison of low dose WBRT $\left(\mathrm{BED}<39 \mathrm{~Gy}_{10}\right)$ versus WBRT control dose $\left(\mathrm{BED}=39 \mathrm{~Gy}_{10}\right)$ : mortality at 6 months

\section{Conclusion}

\section{Surgical resection plus WBRT versus WBRT alone}

Based on the available class I and class II evidence, surgical resection followed by WBRT is an effective treatment for patients with single, surgically accessible, brain metastases who have controlled extra-cranial disease and are in good general condition. Good general condition in the relevant studies was defined as functional independence and spending less than $50 \%$ of time in bed. Patients with disease progression in the 3 months preceding the diagnosis of the brain metastases have a relatively poor survival and poor functional status but still had a significant improvement in survival as a result of surgical resection. Due to the risk of fourth ventricle compression and the 


\begin{tabular}{|c|c|c|c|c|c|}
\hline \multirow[b]{2}{*}{ Study or Subgroup } & \multicolumn{2}{|c|}{ High dose } & \multicolumn{2}{|c|}{ Control dose } & \multirow[b]{2}{*}{ Weight } \\
\hline & Events & Total & Events & Total & \\
\hline Chatani 1985 & 29 & 34 & 20 & 35 & $10.6 \%$ \\
\hline Chatani 1994 & 27 & 46 & 25 & 46 & $8.8 \%$ \\
\hline Komarnicky 1991 & 132 & 216 & 138 & 212 & $28.4 \%$ \\
\hline Kurtz 1981 & 99 & 153 & 98 & 156 & $24.7 \%$ \\
\hline Murray 1997 & 136 & 216 & 128 & 213 & $27.6 \%$ \\
\hline Total $(95 \% \mathrm{Cl})$ & & 665 & & 662 & $100.0 \%$ \\
\hline Total events & 423 & & 409 & & \\
\hline \multicolumn{6}{|c|}{ Heterogeneity: $\mathrm{Tau}^{2}=0.01 ; \mathrm{Chi}^{2}=6.88, \mathrm{df}=4(\mathrm{P}=0.14) ; \mathrm{I}^{2}=42 \%$} \\
\hline \multicolumn{6}{|c|}{ Test for overall effect: $Z=0.86(P=0.39)$} \\
\hline
\end{tabular}

Risk Ratio Risk Ratio

$\mathrm{M}-\mathrm{H}$, Random, $95 \% \mathrm{Cl}$

$1.49[1.08,2.05]$

$1.08[0.75,1.55]$

$0.94[0.81,1.09]$

$1.03[0.87,1.22]$

$1.05[0.90,1.22]$

$1.05[0.94,1.18]$

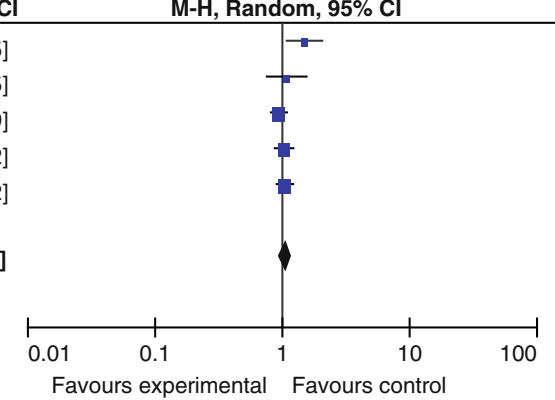

Fig. 3 Comparison of high dose WBRT (BED > $\left.39 \mathrm{~Gy}_{10}\right)$ versus WBRT control dose (BED = $\left.39 \mathrm{~Gy}_{10}\right)$ : mortality at 6 months (Note: extraction of data for Komarnicky trial is based on the $\mathrm{K}-\mathrm{M}$ curve)

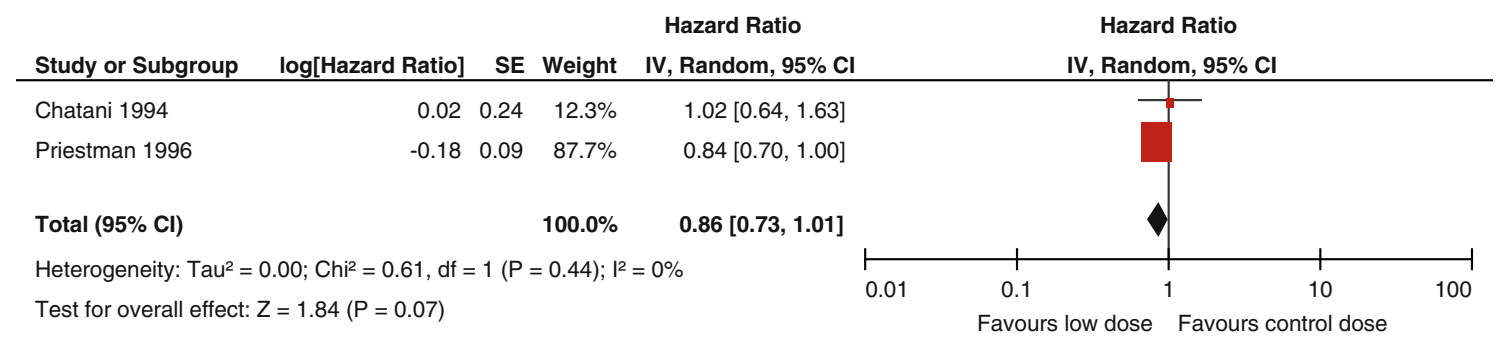

Fig. 4 Comparison of low dose WBRT $\left(\mathrm{BED}<39 \mathrm{~Gy}_{10}\right)$ versus WBRT control dose $\left(\mathrm{BED}=39 \mathrm{~Gy}_{10}\right)$ : overall survival

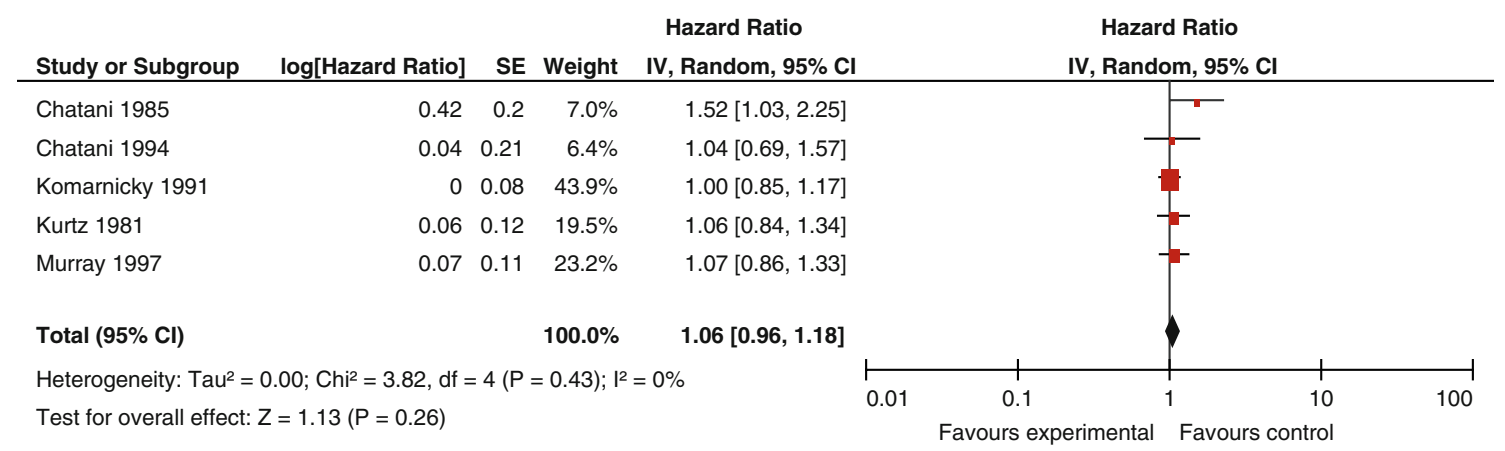

Fig. 5 Comparison of high dose WBRT $\left(\mathrm{BED}>39 \mathrm{~Gy}_{10}\right)$ versus WBRT control dose (BED = 39 Gy): overall survival

subsequent increase in intracranial pressure, surgery should be particularly considered if there is a brain metastasis situated within the posterior fossa.

Surgical resection plus WBRT versus surgical resection alone

The surgical resection guideline paper by Kalkanis et al. [1] outlines in detail the evidence supporting the addition of WBRT after surgical resection. Please refer to this paper for a further discussion of why the combined modalities of surgical resection followed by WBRT represent a superior treatment option, in terms of improving tumor control at the original site of the metastasis and in the brain overall, when compared to surgical resection alone
If WBRT is used, is there an optimal dosing/ fractionation schedule?

There is class I evidence that altered dose/fractionation schedules of WBRT do not result in significant differences in median survival, local control or neurocognitive function when compared to "standard" WBRT dose/fractionation. (i.e., $30 \mathrm{~Gy}$ in 10 daily fractions or a BED of $39 \mathrm{~Gy}_{10}$ ).

If WBRT is used, what impact does tumor histopathology have on treatment outcomes?

Only one small case series (class III evidence) met the eligibility criteria for the question addressing the impact of histopathology on WBRT treatment outcomes. Further 
Table 4 Study evaluating WBRT treatment outcome by histopathology

First author (year): Sundström (1998) [29]

\begin{tabular}{ll}
\hline Study characteristics & Study outcomes \\
\hline Study design: case series & Primary outcome: survival \\
& \\
Inclusion criteria: & Median survival by primary tumor type: \\
Pts treated with WBRT for BM diagnosed by CT or & Breast: 7 months (range 1-62 months) \\
MRI & Lung: 4 months (range 1-21 months) \\
Minimum midline dose to the whole brain of at least & Renal cell: 4 months (range 2-34 months) \\
25 Gy & Melanoma: 3 months (range 1-6 months) \\
& Other primaries: 4 months (range 1-9 months) \\
& (Survival curves: $P$-value not reported) \\
Interventions: & Tumor control: not reported
\end{tabular}

WBRT [mean dose 30 Gy (range 25-40 Gy) in 1.8-

3 Gy fractions]

Median follow-up: not reported

\# Male:

Median time to recurrence of brain metastases: not reported

Breast: 0/19, lung: 26/35, renal cell: 4/9, melanoma: 6/6, other: $6 / 6$

Median age (range):

Breast: 53 years (39-77 years)

Lung: 64 years (43-78 years)

Renal cell: 61 years (41-69 years)

Melanoma: 61 years (39-62 years)

Other: 61 years (50-71 years)

\# Of brain metastases:

Breast: 1 BM 9/19, 2 BM 4/19, >2 BM 6/19

Lung: 1 BM 15/35, 2 BM 5/35, >2 BM 15/35

Renal cell: 1 BM 3/9, 2 BM 2/9, >2 BM 4/9

Melanoma: 1 BM 3/6, 2 BM 0/6, >2 BM 3/6

Other: 1 BM 3/6, 2 BM 2/6, >2 BM 1/6

Extra-cranial disease: Extra-cranial metastases:

Breast: $17 / 19$

Lung: 6/35

Renal cell: $5 / 9$

Melanoma: 4/6

Other: $5 / 6$

Baseline functional performance:

WHO classification (0 (best) to 4 (worst)

Performance status (PS):

Breast: PS 0-1 9/19, PS 2 5/19, PS 3 5/19

Lung: PS 0-1 10/35, PS 2 16/35, PS 3 9/35

Renal cell: PS 0-1 2/9, PS 2 5/9, PS 3 2/9

Melanoma: PS 0-1 6/6

Other: PS 0-1 3/6, PS 2 1/6, PS 3 2/6

AANS American Association of Neurological Surgeons, $B M$ brain metastases, CNS Congress of Neurological Surgeons, $C T$ computed tomography, MRI magnetic resonance imaging, NA not available, Pts patients, WBRT whole brain radiation therapy, WHO World Health Organization 
studies in this area are needed before any recommendations can be made.

Key issues for future investigation

There have been numerous studies comparing various dose/ fractionation schemes for WBRT. Unless future studies incorporate more sophisticated measures of neurocognitive outcome there is little need to repeat these studies. There are, however, very few studies evaluating the effectiveness of WBRT for one histopathological type versus another. Future studies of WBRT explicitly addressing treatment outcomes for well-defined patient groups by different tumor types are needed.

The following is a list of major ongoing or recently closed randomized trials pertaining to the use of whole brain radiation therapy that evaluate treatment comparisons addressed by this guideline paper for the management of newly diagnosed brain metastases.

1. Brain metastases study: radiotherapy schemes in the treatment of brain metastases

Official Title: To determine which of two radiotherapy brain fractionation schemes is superior in the treatment of brain metastases

Status: Completed

Clinicaltrials.gov Identifier: NCT00138788

Principal Investigator: Associate Professor, Peter H

Graham, Cancer Care Centre, St George Hospital

Location: Australia

Sponsors and Collaborators: St George Hospital, Australia

\begin{abstract}
Acknowledgments We would like to acknowledge the contributions of the McMaster Evidence-based Practice Center (EPC), Dr. Parminder Raina (Director). Dr. Lina Santaguida (Co-Associate Director, Senior Scientist) led the EPC staff, which was responsible for managing the systematic review process, searching for and retrieving, reviewing, data abstraction of all articles, preparation of the tables and the formatting and editing of the final manuscripts.
\end{abstract}

Disclaimer of liability The information in these guidelines reflects the current state of knowledge at the time of completion. The presentations are designed to provide an accurate review of the subject matter covered. These guidelines are disseminated with the understanding that the recommendations by the authors and consultants who have collaborated in their development are not meant to replace the individualized care and treatment advice from a patient's physician(s). If medical advice or assistance is required, the services of a competent physician should be sought. The proposals contained in these guidelines may not be suitable for use in all circumstances. The choice to implement any particular recommendation contained in these guidelines must be made by a managing physician in light of the situation in each particular patient and on the basis of existing resources.
Disclosures All panel members provided full disclosure of conflicts of interest, if any, prior to establishing the recommendations contained within these guidelines.

Open Access This article is distributed under the terms of the Creative Commons Attribution Noncommercial License which permits any noncommercial use, distribution, and reproduction in any medium, provided the original author(s) and source are credited.

\section{References}

1. Kalkanis SN, Kondziolka D, Gaspar LE, Burri SH, Asher AL, Cobbs CS et al (2009) The role of surgical resection in the management of newly diagnosed brain metastases: a systematic review and evidence-based clinical practice guideline. J Neurooncol. doi:10.1007/s11060-009-0061-8

2. Linskey ME, Andrews DW, Asher AL, Burri SH, Kondziolka DS, Robinson PD et al (2009) The role of stereotactic radiosurgery in the management of newly diagnosed brain metastases: a systematic review and evidence-based clinical practice guideline. J Neurooncol. doi:10.1007/s11060-009-0073-4

3. Robinson PD, Kalkanis SN, Linskey ME, Santaguida PL (2009) Methodology used to develop the AANS/CNS management of brain metastases evidence-based clinical practice parameter guidelines. J Neurooncol. doi:10.1007/s11060-009-0059-2

4. Centre for Evidence-Based Physiotherapy (2009) Physiotherapy Evidence Database (PEDro). http://www.pedro.org.au/. Accessed January 2009

5. Maher CG, Sherrington C, Herbert RD, Moseley AM, Elkins M (2003) Reliability of the PEDro scale for rating quality of randomized controlled trials. Phys Ther 83(8):713-721

6. Patchell RA, Tibbs PA, Walsh JW, Dempsey RJ, Maruyama Y, Kryscio RJ et al (1990) A randomized trial of surgery in the treatment of single metastases to the brain. $\mathrm{N}$ Engl $\mathrm{J}$ Med 322(8):494-500

7. Mintz AH, Kestle J, Rathbone MP, Gaspar L, Hugenholtz H, Fisher B et al (1996) A randomized trial to assess the efficacy of surgery in addition to radiotherapy in patients with a single cerebral metastasis. Cancer 78(7):1470-1476

8. Vecht CJ, Haaxma-Reiche H, Noordijk EM, Padberg GW, Voormolen JH, Hoekstra FH et al (1993) Treatment of single brain metastasis: radiotherapy alone or combined with neurosurgery? Ann Neurol 33(6):583-590

9. Ampil FL, Nanda A, Willis BK, Nandy I, Meehan R (1996) Metastatic disease in the cerebellum The LSU experience in 1981-1993. Am J Clin Oncol 19(5):509-511

10. Rades D, Kieckebusch S, Haatanen T, Lohynska R, Dunst J, Schild SE (2008) Surgical resection followed by whole brain radiotherapy versus whole brain radiotherapy alone for single brain metastasis. Int J Radiat Oncol Biol Phys 70(5):1319-1324

11. Sause WT, Crowley JJ, Morantz R, Rotman M, Mowry PA, Bouzaglou A et al (1990) Solitary brain metastasis: results of an RTOG/SWOG protocol evaluation surgery + RT versus RT alone. Am J Clin Oncol 13(5):427-432

12. Borgelt B, Gelber R, Larson M, Hendrickson F, Griffin T, Roth R (1981) Ultra-rapid high dose irradiation schedules for the palliation of brain metastases: final results of the first two studies by the Radiation Therapy Oncology Group. Int J Radiat Oncol Biol Phys 7(12):1633-1638

13. Chatani M, Matayoshi Y, Masaki N, Inoue T (1994) Radiation therapy for brain metastases from lung carcinoma. Prospective 
randomized trial according to the level of lactate dehydrogenase. Strahlenther Onkol 170(3):155-161

14. Chatani M, Teshima T, Hata K, Inoue T, Suzuki T (1985) Whole brain irradiation for metastases from lung carcinoma. A clinical investigation. Acta Radiol Oncol 24(4):311-314

15. Davey P, Hoegler D, Ennis M, Smith J (2008) A phase III study of accelerated versus conventional hypofractionated whole brain irradiation in patients of good performance status with brain metastases not suitable for surgical excision. Radiother Oncol 88(2):173-176 Update Sept 242008

16. Haie-Meder C, Pellae-Cosset B, Laplanche A, Lagrange JL, Tuchais C, Nogues C et al (1993) Results of a randomized clinical trial comparing two radiation schedules in the palliative treatment of brain metastases. Radiother Oncol 26(2):111-116

17. Komarnicky LT, Phillips TL, Martz K, Asbell S, Isaacson S, Urtasun R (1991) A randomized phase III protocol for the evaluation of misonidazole combined with radiation in the treatment of patients with brain metastases (RTOG-7916). Int J Radiat Oncol Biol Phys 20(1):53-58

18. Kurtz JM, Gelber R, Brady LW, Carella RJ, Cooper JS (1981) The palliation of brain metastases in a favorable patient population: a randomized clinical trial by the Radiation Therapy Oncology Group. Int J Radiat Oncol Biol Phys 7(7):891-895

19. Murray KJ, Scott C, Greenberg HM, Emami B, Seider M, Vora NL et al (1997) A randomized phase III study of accelerated hyperfractionation versus standard in patients with unresected brain metastases: a report of the Radiation Therapy Oncology Group (RTOG) 9104. Int J Radiat Oncol Biol Phys 39(3):571574

20. Priestman TJ, Dunn J, Brada M, Rampling R, Baker PG (1996) Final results of the Royal College of Radiologists' trial comparing two different radiotherapy schedules in the treatment of cerebral metastases. Clin Oncol (R Coll Radiol) 8(5):308-315

21. Sause WT, Scott C, Krisch R, Rotman M, Sneed PK, Janjan N et al (1993) Phase I/II trial of accelerated fractionation in brain metastases RTOG 85-28. Int $\mathbf{J}$ Radiat Oncol Biol Phys 26(4):653-657

22. Bach F, Sorensen JB, Adrian L, Larsen H, Langer SW, Nelausen KM et al (1996) Brain relapses in chemotherapy-treated small cell lung cancer: a retrospective review of two time-dose regimens of therapeutic brain irradiation. Lung Cancer 15(2):171-181

23. Conill C, Jorcano S, Domingo-Domenech J, Gallego R, Malvehy J, Puig $S$ et al (2006) Whole brain irradiation and temozolomide based chemotherapy in melanoma brain metastases. Clin Transl Oncol 8(4):266-270

24. Nieder C, Berberich W, Nestle U, Niewald M, Walter K, Schnabel K (1995) Relation between local result and total dose of radiotherapy for brain metastases. Int J Radiat Oncol Biol Phys 33(2):349-355

25. Nieder C, Nestle U, Niewald M, Schnabel K (1997) Accelerated radiotherapy for brain metastases. Radiother Oncol 45(1):17-22

26. Rades D, Schild SE, Lohynska R, Veninga T, Stalpers LJ, Dunst J (2007) Two radiation regimens and prognostic factors for brain metastases in nonsmall cell lung cancer patients. Cancer 110(5):1077-1082

27. Rades D, Haatanen T, Schild SE, Dunst J (2007) Dose escalation beyond 30 grays in 10 fractions for patients with multiple brain metastases. Cancer 110(6):1345-1350

28. Rades D, Bohlen G, Dunst J, Lohynska R, Veninga T, Stalpers L et al (2008) Comparison of short-course versus long-course whole-brain radiotherapy in the treatment of brain metastases. Strahlenther Onkol 184(1):30-35

29. Sundstrom JT, Minn H, Lertola KK, Nordman E (1998) Prognosis of patients treated for intracranial metastases with wholebrain irradiation. Ann Med 30(3):296-299

30. Noordijk EM, Vecht CJ, Haaxma-Reiche H, Padberg GW, Voormolen JH, Hoekstra FH et al (1994) The choice of treatment of single brain metastasis should be based on extracranial tumor activity and age. Int J Radiat Oncol Biol Phys 29(4):711-717

31. Chatani M, Teshima T, Hata K, Inoue T (1986) Prognostic factors in patients with brain metastases from lung carcinoma. Strahlenther Onkol 162(3):157-161

32. Regine WF, Scott C, Murray K, Curran W (2001) Neurocognitive outcome in brain metastases patients treated with acceleratedfractionation vs. accelerated-hyperfractionated radiotherapy: an analysis from Radiation Therapy Oncology Group Study 91-04. Int J Radiat Oncol Biol Phys 51(3):711-717

33. Epstein BE, Scott CB, Sause WT, Rotman M, Sneed PK, Janjan NA et al (1993) Improved survival duration in patients with unresected solitary brain metastasis using accelerated hyperfractionated radiation therapy at total doses of 54.4 gray and greater. Results of Radiation Therapy Oncology Group 85-28. Cancer 71(4):1362-1367

34. Rades D, Bohlen G, Lohynska R, Veninga T, Stalpers LJ, Schild SE et al (2007) Whole-brain radiotherapy with 20 Gy in 5 fractions for brain metastases in patients with cancer of unknown primary (CUP). Strahlenther Onkol 183(11):631-636

35. Rades D, Kieckebusch S, Lohynska R, Veninga T, Stalpers LJ, Dunst $J$ et al (2007) Reduction of overall treatment time in patients irradiated for more than three brain metastases. Int $\mathrm{J}$ Radiat Oncol Biol Phys 69(5):1509-1513 (update Sept 24 2008)

36. Rades D, Lohynska R, Veninga T, Stalpers LJ, Schild SE (2007) Evaluation of 2 whole-brain radiotherapy schedules and prognostic factors for brain metastases in breast cancer patients. Cancer 110(11):2587-2592

37. Fowler JF (2006) Practical time-dose evaluations, or how to stop worrying and learn to love linear quadratics. In: Levitt SH, Purdy JA, Perez CA, Vijayakumar S (eds) Technical basis of radiation therapy: practical clinical applications, 4th edn. Springer, Berlin, Heidelberg, pp 3-31

38. Jones B, Dale RG, Deehan C, Hopkins KI, Morgan DA (2001) The role of biologically effective dose (BED) in clinical oncology. Clin Oncol (R Coll Radiol) 13(2):71-81 